\title{
Analysis of Risk Factors in the Scope of Distributed Software Team Structure
}

\author{
Canan Batur Şahin ${ }^{1 *}$, Özlem Batur Dinler ${ }^{2}$, Laith Abualigah ${ }^{3}$

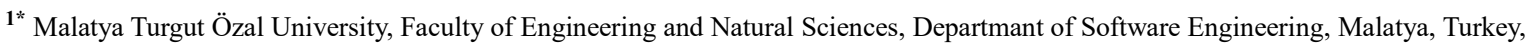 \\ (ORCID: 0000-0002-2131-6368), canan.batur@ozal.edu.tr \\ ${ }^{2}$ Siirt University, Faculty of Engineering, Departmant of Computer Engineering, Siirt, Turkey, \\ (ORCID: 0000-0002-2955-6761), o.b.dinler@siirt.edu.tr \\ ${ }^{3}$ Amman Arab University, Faculty of Computer Sciences and Informatics, Departmant of Software Engineering, Amman, Jordan, \\ (ORCID:0000-0002-2203-4549, aligah.2020@gmail.com
}

( $1^{\text {st }}$ International Conference on Applied Engineering and Natural Sciences (ICAENS)- 1-3 November 2021)

(DOI: $10.31590 /$ ejosat.1004765)

ATIF/REFERENCE: Batur Şahin, C., Batur Dinler, Ö. \& Abualigah, L. (2021). Effect of Risk Factors on Distributed Software Team Structure. European Journal of Science and Technology, (28), 417-424.

\begin{abstract}
The structure of a distributed software team represents a type of development that enables team members to be available at different remote locations throughout the software lifecycle. Therefore, it forms a network of remote sub-teams. Nowadays, the development of software projects with geographically remote teams obligates flexible software development environments. In this case, it is of great significance for software managers to organize and administer the distributed team management well. With the inclination of distributed teams across countries and regions, more stakeholders are being brought onto the scene of software projects. While risk management is the most important assurance of obtaining the expected result from the project, these processes should be considered the common responsibilities and commitment of the stakeholders involved in the project in all fields. The 'in-house' development of the software poses a series of risks. Meanwhile, its partial development in another geography causes the risks in question to increase exponentially. The management of risks should start at the initial stages of the project and continue as a monitoring and follow-up activity throughout the life-cycle of projects. Within the scope of this study, the process steps developed to manage the main risk factors in the distributed team structure in accordance with the Capability Maturity Model Integration (CMMI) instead of the conventional project management approach are explained in detail. Moreover, this study aimed to reveal the components involved in the risk management process regarding the distributed software development.
\end{abstract}

Keywords: Capability Maturity Model Integration, Distant Project Development, Distributed Software Team, Remote Communication, Risk Factors.

\section{Risk Faktörlerinin Dağıtık Yazılım Ekip Yapısı Kapsamında İncelenmesi}

\section{Öz}

Dağıtık yazılım ekip yapısı, ekip üyelerinin yazılımın yaşam döngüsü boyunca farklı uzak yerleşkelerde bulunmasını sağlayan bir gelişim türünü temsil etmektedir. Bu nedenle, uzak alt ekiplerden oluşan bir ağ oluşturmaktadır. Günümüzde yazılım projelerinin coğrafi olarak uzak ekiplerle geliştirilmesi, yazılım geliştirme ortamlarının esnek olmasını zorunlu kılmaktadır. Bu durumda yazılım yöneticilerinin dağıtık ekip yönetimini iyi organize etmeleri ve yönetmeleri büyük önem taşımaktadır. Ülkeler ve bölgeler genelinde dağıtık ekiplerin eğilimi ile yazılım projeleri sahnesine daha fazla sayıda paydaş getirilmektedir. Risk yönetimi, projenin beklenen sonucunu elde etmenin en önemli güvencesi olmakla birlikte, söz konusu süreçler, projede yer alan paydaşların her sahadan ortak sorumlulukları ve taahhüdü olarak düşünülmelidir. Yazılımın 'kurum içi' geliştirilmesi bir dizi riske yol açmaktadır. Aynı zamanda kısmen başka bir coğrafyada gelişmesi söz konusu risklerin katlanarak artmasına neden olmaktadır. Risklerin yönetimi, projenin erken aşamalarında başlamalı ve projelerin yaşam döngüsü boyunca bir izleme ve takip çalışması şeklinde devam etmelidir. Bu çalışma kapsamın da, dağıtık ekip yapısındaki ana risk faktörlerinin geleneksel proje yöntemi yaklaşımı yerine Yetenek Olgunluk Model Entegrasyonu (CMMI) uyarınca yürütülmek üzere geliştirilen süreç adımları detaylı olarak anlatılmaktadır. Ayrıca bu çalışma, dağıtık yazılım geliştirme ile ilgili risk yönetimi sürecinde yer alan bileşenleri ortaya çıkarmayı amaçlamıştır.

Anahtar Kelimeler: Yetenek Olgunluk Modeli Entegrasyonu, Uzaktan Proje Geliştirme, Dağıtık Yazılım Ekibi, Uzaktan İletişim, Risk Faktörleri.

* Corresponding Author: canan.batur@,ozal.edu.tr 


\section{Introduction}

Various companies working globally carry out projects with distributed teams working in distant regions or in different countries. In distributed teams, the most common challenges are security, control, visibility, and communication. Therefore; Distributed teams should work in coordination to overcome these difficulties.

The most important risk group in remote access project management is the risks arising from communication. Because; Direct face-to-face communication is not possible between remote access team members. Therefore, communication between team members is more difficult and more formal. For this reason, the necessary trust environment cannot be created among the team members. In such project management; For a more effective and healthy communication; The infrastructure of various communication tools such as cameras, teleconferencing, instant messenger, video chat, screen sharing (screen sharing software), e-mail, instant message must be installed and widely used.

Distributed Software Development (DSD) includes the work of teams in collaboration for the purpose of achieving project targets. In DSD, it is possible that development sites are physically distributed within a country or worldwide, including numerous countries [6].

Members of teams are separated geographically, work in various time zones, establish simultaneous communication, and exchange information not depending on physical boundaries and time difference [8]. Various problems arise within the group due to the geographical location and different time intervals of the multinational project groups because of working geographically separately. For example; Intra-group communication, sharing and the successful completion of the project pose significant risks for multinational projects. In order to prevent such risks, information management should be provided in a professional manner. The need to divide the teams into regions according to the distributed team organizational structure, to structure the information sharing between teams within a certain time schedule, to organize the management of cultural differences, to organize the work environments and to draw up coordination plans for the studies to produce consistent results, created the need to categorize risk syntheses into different field definitions. Project supervisor; clearly and clearly express and share the work and task distribution between teams. Distributed team members should be aware of the work each team member will be doing and that they do not work in isolation from each other.Using an online tool as Assembla, FogBugz and Jira to track the completed or approved works by team members and other project members during the execution of the project. The risk management procedure in distributed teams comprises from above milestones. In distributed software development processes; effective use of written communication; It reduces project risks arising from the management of the requested changes. Because requests made by written communication are recorded. Determining customer requirements by remote access, not understanding or understanding the requirements clearly creates a high degree of risk for the project.

Four different decision techniques have been synthesized in order to bring the existing team in distributed geographic structures closer to the desired cultural structure. These are Planning, Control, Social integration and Technical integration techniques. Planning techniques; distributed in project design and organization. It is effective in running the contents effectively. Control techniques assist in facilitating the follow-up of process developments across regions and managing discrepancies between associated plans.

Social integration techniques; Increasing the compatibility of team members within a common structure and managing cultural differences between regions. Technical integration techniques; It ensures that the communication and infrastructure technique between the regions is completed and its integrity is increased.

The problems that may arise in distributed software development processes and the problems that pose a high risk for the project; Communication Problems: Problems arising from the lack of clear information flow between project group members. In such projects, synchronous communication tools such as video conferencing should be preferred for a healthy and cheap communication. Coordination Problems: Time, labor, cost, etc. arising from disconnected and incompatible work of project group members. it is a waste of resources. Therefore, the project manager should be in frequent contact with the project group members, motivate the employees and establish a strong coordination among the employees. Control Problems: It is the failure of the project manager to intervene at the right (when required) due to any problems that may occur in the project (for example, time, cost, etc.) Therefore, the project manager should be a good follower by using simultaneous and asynchronous communication tools in distributed team projects. Information Management Problems: Information management in projects developing distributed software is more difficult than nondistributed software development projects. Because; In such projects, management is carried out by remote access. In order to prevent information management problems, firstly, communication problems that may arise both within and outside the group must be resolved and secondly, the information to be transmitted must be conveyed to the right person or persons without misrepresenting it. Technical Process and Infrastructure Problems: It is a basic requirement to prepare the necessary technical process and infrastructure conditions for each project structure in order to carry out projects developed in distributed teams or non-distributed teams. If sufficient technical operation or infrastructure conditions cannot be provided, it makes it inevitable for the project to fail [16].

In recent literature, many opinions have been put forward to overcome the difficulties encountered in risk management with distributed team organization. However, there has not been a comprehensive study on the process steps compatible with Capability Maturity Model Integration (CMMI) developed to eliminate the side effects of the structuring of team organizations in this structure on risk management. In this study, it is emphasized that especially CMMI process steps concentrate on risk management, and the risks are identified and analyzed before they occur within the project. Afterwards, specific risk factors were identified in order to be able to characterize the defined risk areas. Thus, project managers defined risk planning activities designed in distributed team structures throughout the software life cycle, including risk areas and characteristic factors. These factors include the compatibility of the team members' understanding and competency differences, the attitudes, behaviors and the personalities of the team members, the compatibility of the team members with the corporate culture. It is determined according to which style and methods the teams will work as a measure of the distributed geographic functionality of technology as a means of gathering and sharing information. 
The outline of this paper is as follows. In the next section, we provide a related works. Section III provides methodology. We then present results in Section IV, and outlines the summary and conclusion in Section V.

\section{Related Works}

In this section, it is examined how project-, team-, and riskrelated management may affect coordination needs and whether it has been indicated that characteristics influence the performance of teams. [1] conducted a literature review on risk management practices and methods in the design and development of products. The mentioned study also investigated the types of evidence utilized to assess the efficiency of risk management activities. [2] shared the results of an exploratory study on the coordination needs of teams, particularly when unfamiliar or complex tasks are encountered. Finally, this research argues that it is important to satisfy the coordination needs of teams to achieve the targeted performance. (ISO 31010) recommended practices beneficial for practitioners and researchers because they ensure a framework to understand and navigate the literature, which may also assist organizations in tailoring their risk management. [3] investigated the change in coordination through scheduled and unscheduled meetings in the course of time in two large software development programs. The transition from scheduled to unscheduled meetings and vice versa was obtained in the results. [6] suggested a task allocation framework consisting of two stages. The first stage is to identify factors and dependencies, which significantly affect the task allocation decision. The second stage is to suggest a quantitative method, allocating tasks to team members matching the requirements of the task in the best way. Furthermore, this method ensures the quality assessment of task-member assignment in the course and following the completion of the project, towards bringing related risks to a minimum. [9] focused on investigating the resilience of teams influenced by two adversities that were unique to project team composition and project dynamics. [16] performed the development of a comprehensive process compliant with CMMI, the maturity model of the Software Engineering Institute to evaluate and enhance organizational processes. [17] developed an automated decision support system to help practitioners evaluate risks and make a decision on appropriate control strategies. The findings demonstrate that the introduced decision support system provides support in the decision-making process in assessing risks and selecting a control strategy. [7] identified by conducting an empirical study at five various projects of an enterprise and the geographical distance challenges in distributed software development. As a result, it was stated that geographical distancebased challenges constitute risks for communication, coordination, and control process in distributed software development. [10] carried out the integration of the risk management process in the Scrum framework, a commonly utilized agile method. The findings indicated the significance amount of the identified critical risk. [8] conducted a survey of a number of research articles employing soft computing (SC) techniques, primarily in risk management, software quality, software reliability, software maintenance, and project management. [13] conducted an overview of an extensible blockchain enabling decentralized compliance adherence and governance framework for distributed software delivery to introduce transparency and trust in the activities of distributed teams in global software delivery.

\section{Material and Method}

This paper investigates the main approach by addressing the challenges of risk management involved in the structure of distributed team organizations.

\subsection{Process Architecture of Distributed Team Buildings}

Distributed team organization structuring of the risk management process is handled in 3 fundamental steps. Identification and analysis of risk, development of risk reduction planning, and implementation of risk reduction planning are key steps of the process. The realization of the risk management targeted within the framework of the Capability Maturity Model Integration (CMMI), standard allows this architecture to be used by project managers in structuring distributed team organizations. The Figure 1 represents the risk management process. Defining the risks and completing their analysis, which is the first process step in the proposed architecture structure, greatly helps the managers of the distributed team structuring. Thus, the management perspective has been shaped by architectural structuring within the framework of the proposed architecture, by making the probability calculation of the risks that have been defined and categorized, considering their possible effects and grading the priorities. In case the comprehensive knowledge or communication of the project manager for each different region is not sufficient, it is very important that each step that constitutes the architectural configuration is adopted by the team members within the distributed region.

Reflecting the risk assessments created within each distributed region from local estimates to the whole project is an important part of another step. In order to achieve this, it is necessary to reveal the differences of experience and perspective for each distributed region and to increase the negotiation and project meetings on the grading of the foreseen priorities. It is ensured that project managers are also distributed risk data, which are rated, to the whole organization, and it is ensured that the comparison of the risk management of sub-projects is learned between independent projects. This factor helps distributed team managers to increase measures and reduce risks within the framework of risk reduction planning. The risk reduction planning to be developed should be supported within the scope of the synthesized decision techniques list in the context of the question of how to implement the measures in each risk area in Table 1. Each distributed team member should have adopted new solution proposals with improved techniques to the questions of what kind of measures should be taken within the framework of risk reduction planning and how these measures will be implemented within the current scope. Finally, it will be concluded by deciding which practical approaches the risk reduction planning will be implemented in line with the goals of distributed team members. This completion process is achieved by the responsibilities of the distributed team members, resource allocation and the determination of milestones related to the key elements for implementation.

\subsection{Process Steps of Distributed Team Buildings}

Distributed team organization structuring of the risk management process is handled in 3 fundamental steps. Identification and analysis of risk, development of risk reduction planning, and implementation of risk reduction planning are key steps of the process. 


\subsubsection{Risk Identification and Analysis}

A software risk refers to a feature of a development task, environment, or process, which causes the possibility of project failure to increase in case of being ignored [15]. Risk identification and analysis within distributed team organizations is within a certain level of difficulty. Sharing the risks to distributed regions and team members according to their types and meanings brings problems that are not easy to solve. In Table-1, 8 different risk areas categorized according to risk areas and specific risk factors characterized for distributed team organization structures are defined.

Risk factors are characterized by low, medium and high level indicators. First of all, team members in each local area will use the defined and analyzed risk table in Table-1. Afterwards, the risk managers will discuss the results of the local assessment of risks for each region and combine the risk assessments and priorities of the entire project in the project meetings to be held in the whole project. Risk management team employees have identified each risk factor in Table-1 with two different probability values. The first of these evaluated the unmet probability of the expected as $\mathrm{P}$ (UO) and the second as the loss L (UO) affected by this probability. Each determined value can be graded with a scaler value in the range of 0-8 and categorized as low in the range of 0 2 , medium in the range of 3-5 and high in the range of 6-8. Quality indicators are expected to be consistent with probability values in Table-1. Afterwards, the severity of risk exposure (RE) is calculated for each risk factor through web-based tools.

$$
\mathrm{RE}=\mathrm{P}(\mathrm{UO}) * \mathrm{~L}(\mathrm{UO})
$$

\subsubsection{Development of Risk Mitigation Planning}

Risk analysis, risk identification, control, and mitigation represent the primary activities of risk management [10]. One of the main success factors of risk reduction planning is the importance given to defining high priority risk areas. In this way, comprehensive risk prevention planning under an effective risk management is supported. It has been developed within the framework of risk prevention planning of 8 different risk areas, categorized according to their fields within the framework of synthesized decision techniques. There are some inconsistencies between the defined techniques assigned to some existing situations within the developed plan. For example, while the methods between local regions are recommended to be standard and educational, on the other hand, the necessity to support the differences in methods between local regions is proposed as a separate technique. Unfortunately, this inconsistency has emerged as a more dangerous risk factor. For this reason, instead of creating plans within the framework of general synthesized decision techniques, it is suggested that process users should improve the decision techniques used within the company or create new decision techniques. Team-workers are expected to develop risk reduction planning and then reflect overall project risk assessments throughout the project in negotiations or project meetings. Risk management is showed in Figure 2.

3.2.3. Development of Risk Mitigation Planning In risk management, it is very important to reach a level that can be managed within the scope of the implementation plan. In other words, for the implementation of the risk reduction plan specific to each rated risk area, the plan must be kept under control with the activities to be defined under each risk area. Figure 2, represents the basic risk management process.

Structuring the risk reduction plan includes 5 basic elements It is set within a certain framework with its comprehensive follow-up:

The first of these is the purpose, in other words, the reasons for defining risk assessments, the second is when, how and at which event milestones and deliveries will be taken into account by the team, and the third is the responsibilities, among which distributed regional team employees the activities will be shared, and distributed team members, from which environment to where they will transfer activities. Fourth, Method, how to apply synthesized techniques defined for each risk area, fifth, resources, it is stated that how much resource transfer or allocation will be made to which risk area within the scope of budget estimation. The risk reduction plan to be applied for each local area should be combined by the project manager and the whole project should be integrated on the basis of the risk management plan.

Distributed teams need to decide how often they will use the risk management process and make sure that each activity creates its own documentation and sub-component activities within the scope of this process.

\section{Results and Discussion}

\subsection{Implementing Empirical Study}

Distributed In this paper, we observe the effects of risk process management on the distributed software project, which includes foreign-language data of foreign countries, where there are branches in many parts of the country, is implemented on the basis of the Information Technology (IT) department. Since banking is a risk taking and management business within its core functions, the risks arising from banking activities should be properly understood, measured and managed well. Although digitizing the risk is very important, integrating the risks on the basis of distributed groups and determining the risk-taking tendency and risk-taking capacity as a whole necessitates the planning of a difficult process management. This requirement factor reveals the necessity for the risk reduction planning to be developed by the IT platforms of banks to comply with other bank standards and to develop effective strategies in all branches. 
Figure 1: Risk Management Process [16].

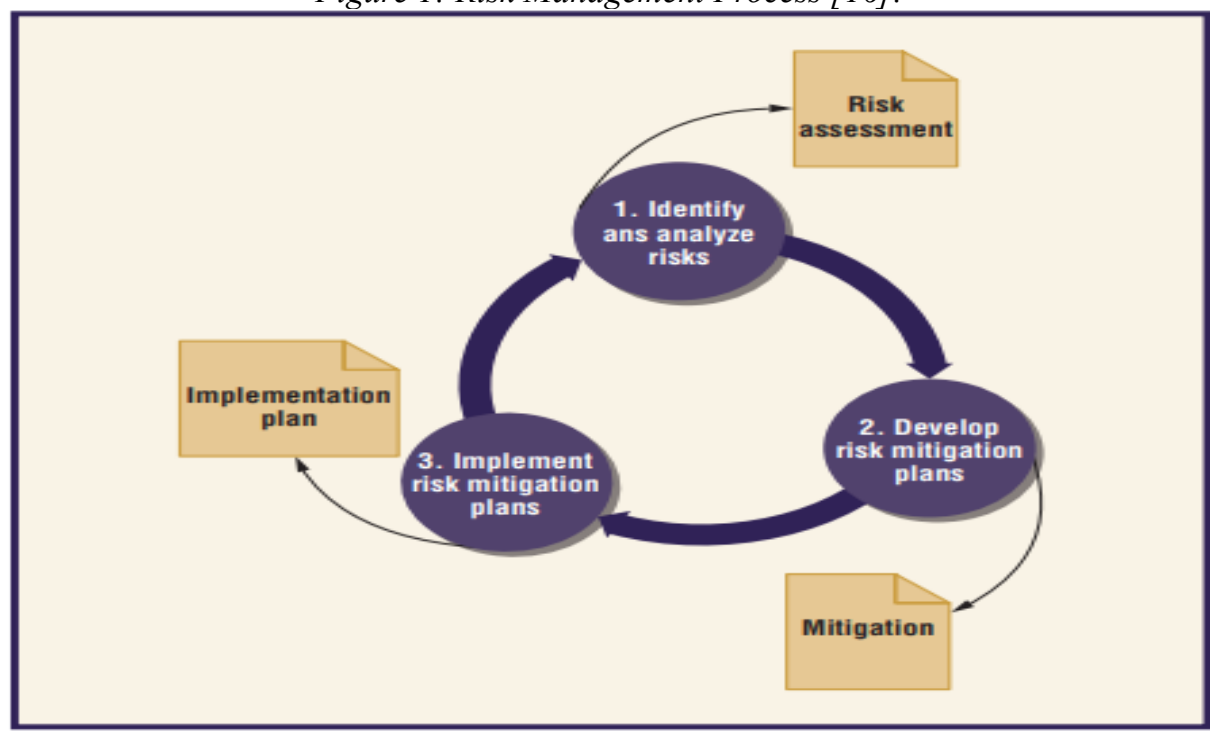

Table 1. Identification and analysis of risks in distributed team structures [16].

\begin{tabular}{|c|c|c|c|}
\hline \multirow{2}{*}{ Risk Areas } & \multicolumn{3}{|c|}{ Risk factor and related question } \\
\hline & Low Risk & Medium Risk & High Risk \\
\hline job distribution & Capacity & To overcome the difficulties & serious capacity gap \\
\hline Knowledge Management & All agency & some units & serious (emergency) units \\
\hline Geographical Distribution & limited distance & determined distance & Overrun distance \\
\hline Team Organizational Structure & Required Cooperation & majority cooperation & General disconnection \\
\hline Cultural distribution & Little cultural difference & To overcome the difficulties & cultural difference is high \\
\hline stakeholder relations & high relationship & cultural difference is medium & low relationship \\
\hline Communication infrastructure & General support & middle affair & a few supports \\
\hline Technological infrastructure & Safe infrastructure & certain support & low infrastructure \\
\hline
\end{tabular}

The bank's standard-level IT platform consists of many subproject components. This includes the information that the project, where the risk management process planning will be implemented, will be completed at the end of a 1-year project period within the scope of the integrated project with 20 separate sub-projects and more than 500 team members. Project team employees provide services within the IT structure of the bank in 4 different distributed regions. As it requires more IT experts due to the breadth of the integrated project, it also needs outsourcing from foreign branches that cover other different languages. The organizational structure of the IT structure of the bank shows that 7 out of 20 different sub-projects are distributed to 3 different organizational structures, 11 are within the IT body, and 2 are structured as outsourcing providers.

The IT department management of the bank attaches great importance to the problems faced by the software development team in distributed regions. Each manager involved in project integration starts the process at the requirement analysis phase. Each sub-project manager completes the local risk assessments for project negotiation within their own distributed region, as in Table-I.
At this point, project integration managers decide to repeat the risk management process in the frequency range during the project life cycle. Some sub projects are unable to organize faceto-face meetings. For this reason, meetings can be held by teleconferencing or by sharing the results on the computer via web-based tools.

They support the meeting with the opinions of those who do not participate in the risk assessed by providing an open, sincere In order to increase motivation at the meeting, a project manager expects the volunteers to explain the assessed risk tools by showing the details of their risk assessment. and reliable communication environment and those who have previous experience about this risk assessment. Distributed team managers can be enabled to close the gap between the cultural difference between distributed teams with a similar initiative. In each distributed zone risk assessment, the project integrator manager is invited to meet with all local area managers.

A similar procedure is applied to each sub-project negotiation. In the first meeting held during the requirement analysis phase, each project manager is required to define the 
distribution of the cultural differences of the distributed team units under the risk area of each sub project. Thus, the grading of risk areas according to their importance is realized more clearly. Project managers evaluate the activity distributions according to the risk areas defined as high level of importance.
While the frequency of activity distribution and cultural distribution throughout the project life cycle is included in the high-rated risk area, the communication infrastructure and geographic distribution frequency are included in the low-rated risk area.

Figure 2: Risk Management [10].

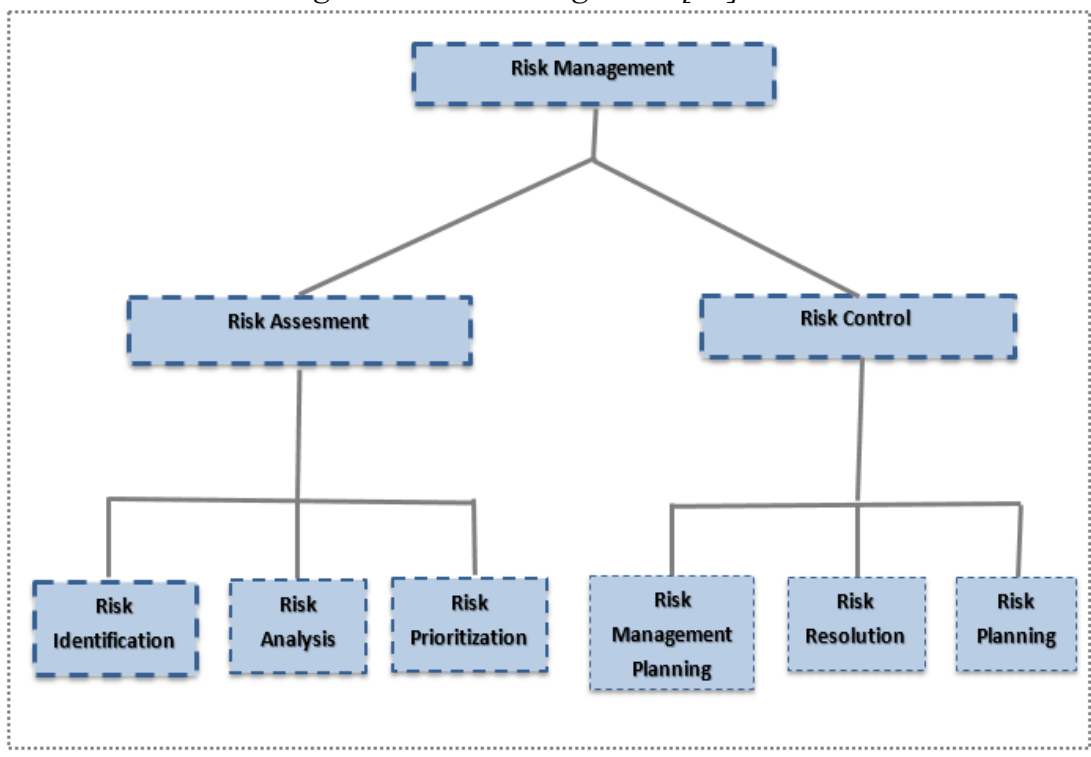

Figure 3:Team-external coordination patterns [2].
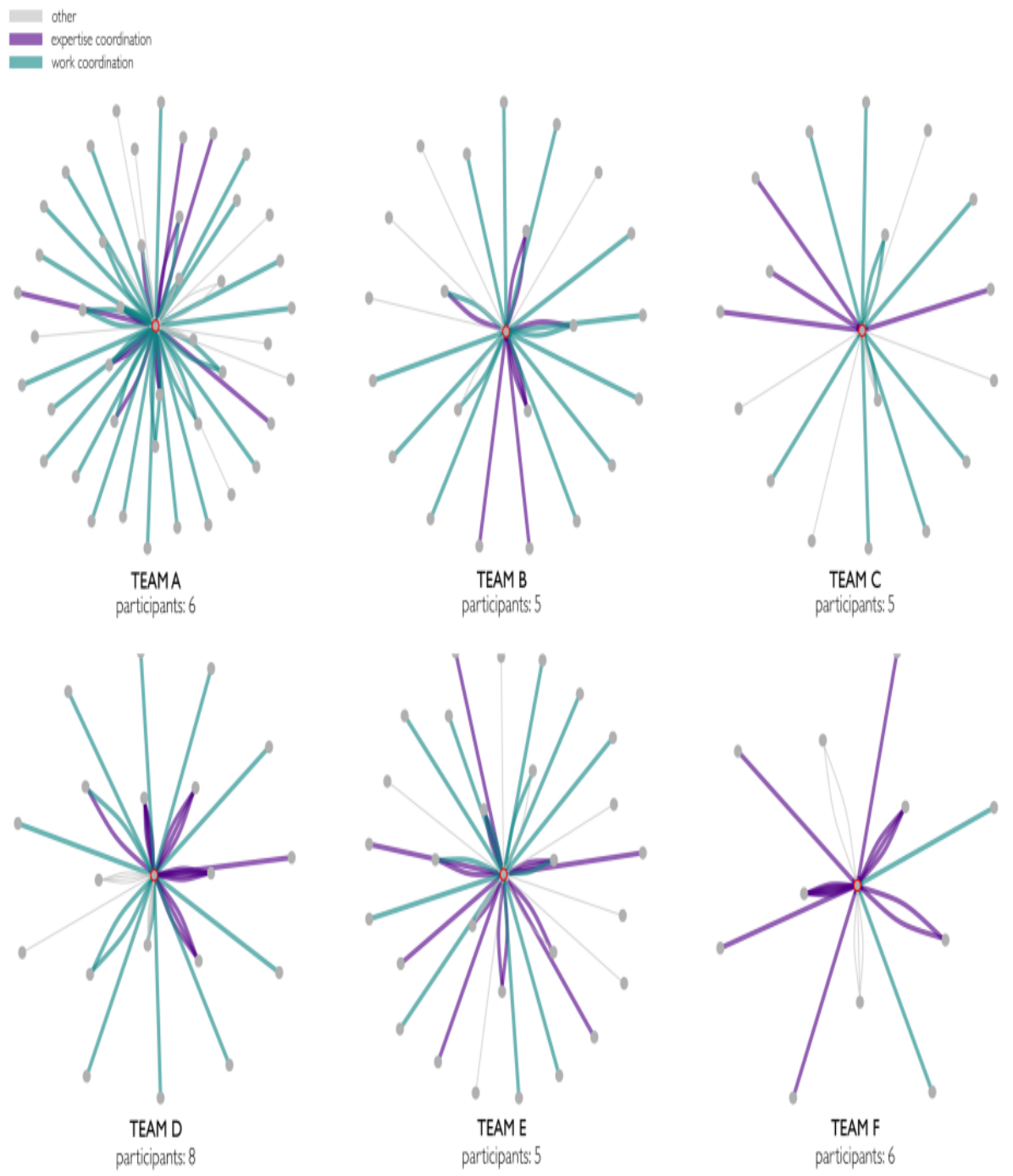

TEAMF

participants: 6 
Within the scope of the integrated project, at the end of the risk assessment meetings, the details of 5 important items are written by the risk management team members. For example, management of cultural differences within the local area, implementation of risk management process planning by team members in local regions, etc. How to realize the function of the integration of distributed team organizations is one of the main goals for team culture structuring. The distributions of cultural differences between the risk groups and the relations between the milestones are evaluated within the scope of special dates scheduled in the negotiations. Within the scope of each meeting, the team members who are responsible for the creation of the cultural infrastructure make the necessary notes and in addition to this approach, the team members can also take the necessary notes within the scope of their interests. At the end of the negotiation, the negotiation participants are expected to submit their estimation evaluations about each local team twice a month. After two months, risk management team members reassess the cultural distribution risk group. Within the scope of the assessment, it is observed whether there is a decrease from high risk level to medium risk level. In this way, the necessary initiatives to reduce misunderstandings based on cultural differences are facilitated by increasing the cooperation between team members. Figure 3 shows as an example of individual team-external coordination patterns.

\section{Conclusions and Recommendations}

Global competition caused an increase in the need for flexibility, and access to global resources and significant financial gains lead businesses to take part in software projects that are geographically distributed [15]. The instructions that should be followed carefully within the scope of the distributed team risk management process should be arranged in accordance with the project team structure and providing options. Distributed team risk management requires the ability to deal with many challenges. For this reason, it is necessary to be able to establish a risk management structure suitable for the organization or project structure and at the same time to see the elimination of risk factors by team employees as an important value on the risk management process as much as planning and entrepreneurship. Distributed team structuring can vary in size and complexity. In some cases, only a few team members from each local area are needed, in other cases all the team members of each local area are needed. Therefore, ensuring secure and transparent communication regardless of the number of team members and the complexity of the risk management process is a vital requirement for the risk management process. Risk management can be organized differently according to various options on the basis of process structuring. In this context, many options may sometimes not be compatible with the process architecture. For example, more synthesized techniques may need to be used within the framework of the risk reduction plan. Project management is not limited to structuring and managing risk process management within the scope of a distributed team. Risk management is just one of many key disciplines of project management. A general project management consists of combining many processes within itself. Using a suitable software system can be a serious support in process and plan integration. To be able to carry out an effective distributed team management in the implementation phase of the risk management process requires having skills at a certain standard level. Having complementary capacities to adapt to changes in the face of many possibilities such as continuing progress throughout the project life cycle, being included in a new local area, will reduce the risks of distributed teams and this success will be reflected in the project management process to the same extent.

In this paper, it is aimed to present the risk management process recommendations for the management of the risk assessments of the managers in a comprehensive way throughout the risk management process in a systematic manner, especially the control of the risks encountered in the distributed team organization structure, in line with the directives. this paper, within the scope of the literature review and software development examples developed within the scope of the distributed team structure, it is presented for your information in the hope that the managers will avoid possible mistakes and manage many successful project processes.

\section{Acknowledge}

This article does not contain any studies with human participants performed by any of the authors.

\section{References}

[1] Oehmen J., Guenther A., Herrmann J., Schulte J., and Willumsen P., (2020) Risk Management in Product Development: Risk Identification , Assessment, and Mitigation - A Literature Review, Proceedings of the Design Society: DESIGN Conference, vol. 1, pp. 657-666. doi:10.1017/dsd.2020.27.

[2] Sablis A., Smite D., Moe N.B., (2021). Team-external coordination in large-scale software development projects, Journal of Software Maintenance, 33(3), https://doi.org/10.1002/smr.2297.

[3] Dingsøyr T., Rolland K., Moe N. B., (2017). Coordination in multi-team programmes. An investigation of the group mode in large-scale agile software development, Procedia Comput Sci. 2017;121:123-128.

[4] (2009). IEC/ISO 31010 Risk management - Risk assessment techniques, International Organization for Standardization, Geneva. Google Scholar.

[5] (2018). ISO 31000:2018 Risk management - Guidelines, International Organization for Standardization, Geneva, Google Scholar.

[6] Aslam W., and Ijaz F., (2018). A Quantitative Framework for Task Allocation in Distributed Agile Software Development, in IEEE Access, vol. 6, pp. 15380-15390, 2018, doi: 10.1109/ACCESS.2018.2803685.

[7] Kahya M.D. and Seneler Ç., (2018). Geographical Distance Challenges in Distributed Agile Software Development: Case Study of a Global Company, 3rd International Conference on Computer Science and Engineering (UBMK), doi: 10.1109/UBMK.2018.8566591.

[8] Iftikhar A., Musa S., Alam M., M. M. and Ali S. M. Su'ud, (2018). A survey of soft computing applications in global software development, IEEE International Conference on Innovative Research and Development (ICIRD), pp. 1-4, doi: 10.1109/ICIRD.2018.8376330.

[9] Cavrak I. and Bosnic I., (2018). Team Resilience in Distributed Student Projects, IEEE/ACM 13th International 
Conference on Global Software Engineering (ICGSE), pp. 107-115, 2018.

[10] Hammad M., and Inayat I., (2018). Integrating Risk Management in Scrum Framework, International Conference on Frontiers of Information Technology (FIT), pp. 158-163, doi: 10.1109/FIT.2018.00035.

[11] Behnke R. P. et al., (2019). Lowering Electricity Access Barriers by Means of Participative Processes Applied to Microgrid Solutions: The Chilean Case, in Proceedings of the IEEE, vol. 107, no. 9, pp. 1857-1871, Sept., doi: 10.1109/JPROC.2019.2922342.

[12] Filho R. N., et al., (2019). Collaboration Tool for Distributed Open Source Verification. ACM/IEEE 14th International Conference on Global Software Engineering (ICGSE), 139142. Doi: 10.1109/ICGSE.2019.00034.

[13] Singi K., Kaulgud V., Bose R. P. J. C., and Podder S., (2019). CAG: Compliance Adherence and Governance in Software Delivery Using Blockchain, IEEE/ACM 2nd International Workshop on Emerging Trends in Software Engineering for Blockchain (WETSEB), pp. 32-39, doi: 10.1109/WETSEB.2019.00011.

[14] Mirsaeedi E. and Rigby P. C., (2020). Mitigating Turnover with Code Review Recommendation: Balancing Expertise, Workload, and Knowledge Distribution, IEEE/ACM 42nd International Conference on Software Engineering (ICSE), pp. 1183-1195, doi: 10.1145/3377811.3380335.

[15] Persson J. S., Mathiassen L., Boeg L., Madsen J., T. S., and Steinson F., (2009). Managing Risks in Distributed Software Projects: An Integrative Framework, in IEEE Transactions on Engineering Management, vol. 56, no. 3, pp. 508-532, Aug, doi: 10.1109/TEM.2009.2013827.

[16] Persson J., and Mathiassen L., (2010). A Process for Managing Risks in Distributed Teams, in IEEE Software, vol. 27, no. 1, pp. 20-29, Jan.-Feb, Doi: 10.1109/MS.2009.157.

[17] Aslam A., et al., (2017). Decision support system for risk assessment and management strategies in distributed software development, IEEE Access, vol. 5, pp. 20349-20373. 